\title{
Aetiology, antifungal susceptibility, risk factors and outcome in 201 fungaemic children: data from a 12-year prospective national study from Slovakia
}

\author{
VLADIMIR KRCMERY, LADISLAV LAHO\|, MÁRIA HUTTOVA, ADRIANA ONDRUSOVA,

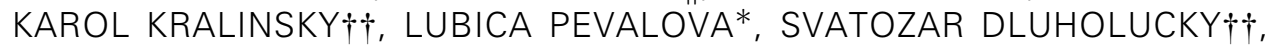 \\ MÁRIA PISARČÍKOVÁ§, JURAJ HANZEN*, JOZEF FILKA§, DÁŠA SEJNOVÁ†, ANNA LIŠKOVÁ††, \\ ANNA PURGELOVÁ††, ZUZANA SZOVENYOVÁł and PAVOL KOREN**
}

Department of Chemotherapy, Postgraduate Medical School and University of Trnava, Bratislava, *Department of Paediatrics, Postgraduate Medical School and Derer's Faculty Hospital and Paediatric Surgery, Children's University Hospital, Bratislava, †Department of Paediatric Oncology, Bratislava, $\$$ Department of Paediatric Oncology and Microbiology, Košice, \$Clinic of Paediatrics, UniversityHospital, Košice, \|Clinic of Paediatrics, Postgraduate Medical School, Banská Bystrica and Nitra, ${ }^{* *}$ Department of Paediatrics, Infectious Diseases, Microbiology, School of Public Health, University of Trnava, Slovakia and ††Department of Health Management and Statistics, University of Scranton, PA, USA

\begin{abstract}
A total of 201 cases of fungaemia in children in a 12-year national survey from seven University Paediatric Clinics in Slovakia in 1990-2001 was assessed to determine risk factors, therapy and outcome, and to compare those cases with fungaemia in 130 adult cancer patients studied in a similar survey. Four univariate analyses were performed to assess differences in aetiology, antifungal susceptibility and outcome between fungaemia in neonates and paediatric intensive care unit (ICU) patients as well as between paediatric and adult cancer patients with fungaemia. There was a significant difference in aetiology and antifungal susceptibility between the subgroups of children with fungaemia: $83.3 \%$ of neonates versus $40.2 \%$ in children with cancer were due to Candida albicans. None of the non-albicans Candida spp. (NAC) in neonates but $23.5 \%$ of NAC isolates from children with cancer were resistant to fluconazole. $C$. albicans caused 144 (71.1\%) episodes and NAC 48 (23.7\%) episodes. Trichosporon beigelii, Blastoschizomyces (Trichosporon) capitatus, Rhodotorula rubra and Cryptococcus laurentii were found less frequently in neonates than in children with cancer $(\mathbf{1 8 . 8 \% )})$. There were not many differences in risk factors between paediatric fungaemia and adult cancer fungaemia except $C$. albicans aetiology, corticosteroid use in therapy, breakthrough fungaemia after ketoconazole prophylaxis and meningitis as a complication, which were observed significantly more frequently among children than in adults, both with cancer and fungaemia. Thirty-three of the paediatric fungaemias were breakthrough cases and appeared frequently in children with cancer. Fifty-one $(25.1 \%)$ children died with fungaemia (attributable mortality) and $25(12.7 \%)$ due to underlying disease with fungaemia; overall mortality was $37.8 \%$ and there was no significant difference in death rates between the subgroups of paediatric patients (neonates, children in ICUs and children with cancer).
\end{abstract}

\section{Introduction}

Fungaemia is an increasingly common complication in patients in intensive care units (ICUs), both in adults and children with various severe underlying diseases [1]. However, its incidence in children is much lower

Received 6 Sept. 2000; revised version received 14 May 2001; accepted 11 July 2001.

Corresponding author: Professor V. Krcmery. than in adults $[2,3]$. Paediatric patient populations at risk mainly include premature neonates who receive total parenteral nutrition (TPN), are given ventillatory support (AV) or have central venous catheters (CVC); children with cancer subjected to major surgery or aggressive antineoplastic chemotherapy with ensuing neutropenia or who are treated with steroids or antibiotics, or who undergo bone marrow transplantation (BMT) [4-7]. Although there are numerous reports on risk factors, therapy and mortality of 
fungaemia in adults [8-11], data on paediatric fungaemia are limited $[2,3]$. Several case reports and several series on fungaemia in homogeneous paediatric patient populations have been published during the last 12 years, mainly in neonates $[1-7,12-16]$. However, only three reports included more than 40 children [2, 17, 18]. Walsh et al. [1] reported 27 cases of fungaemia in HIV-positive children, Kim-Stamos and Rowley [2] reported 70 cases and Roilides et al. [3] described 32 children from paediatric intensive care units. Our group briefly summarised 80 neonates with fungaemia [17] and separately analysed 21 children with cancer [18] and no breakthrough fungaemias as well [19]. The authors of all these studies have found similar aetiology and risk factors, but lower overall mortality in comparison with adults [9-11]. The aim of this study was to review all cases of paediatric fungaemia seen in all major paediatric clinics and departments in Slovakia in the last 12 years (National Survey), to assess risk factors, aetiology, therapy, complications and outcome, and to compare them to cases of fungaemia in adults.

\section{Patients and methods}

\section{Study design}

In all, 201 cases of fungaemia, defined as single or multiple positive blood culture (BC) for fungi plus clinical or laboratory symptoms of infection, seen in all seven university paediatric clinics and departments in Slovakia were included in the study. From 1 Jan. 1989 until 1 Jan. 2001 (12 years), prospective protocols of children with fungaemia were completed. The following risk factors were recorded: aetiology, underlying disease, neonatal age (defined as age $<28$ days), sex, prematurity, neutropenia, birth weight, CVC, TPN, AV, prior therapy with corticosteroids, cytotoxic drugs, antibiotic prophylaxis and therapy, prior antifungal prophylaxis and therapy, prior colonisation with yeasts, number of $\mathrm{BC}$, day when the first positive $\mathrm{BC}$ appeared, type of neoplasia and length of stay in the ICU. Complications, length and type of therapy, and outcome were also recorded. Attributable mortality was defined as death with fungaemia. Autopsy was not used for assessment of attributable mortality, because only 12 children (c. 36\%) had autopsy. Univariate and multivariate analyses were performed, comparing two subgroups among paediatric fungaemias to assess differences in aetiology, risk factors and outcome.

\section{Blood culture}

Routine $\mathrm{BC}$ were obtained in all seven clinics, which were served by microbiological laboratories (Bratislava, B. Bystrica, Košice) with Bactalert or BACTEC (BBL) blood culture systems, if fever or other clinical signs and symptoms of infection appeared (e.g., in neonates: hypothermia, lung infiltrates, hypertension). Colonies growing on blood or Sabouraud agar plates were identified by Mycotube (Hoffman La Roche Diagnostica) and Vitek Jr system (Vitek, bioMérieux, Hazelwood, MO, USA). Antifungal susceptibility was not routinely determined in every case (data are from a limited number of children) because no methods for such testing were available until 1997 and not all strains were stored. Therefore, only limited data on susceptibility to antifungal agents for isolates from children are presented. Susceptibility to fluconazole was determined by the disk diffusion method (DDM) and a $25-\mu \mathrm{g}$ fluconazole disk was used in the laboratories in Slovakia.

\section{Statistical analysis}

A computerised program, EPI-INFO K21 of the Department of Health Management, University of Scranton and University of Trnava, was used for four univariate analyses comparing aetiology, antifungal susceptibility, risk factors and outcome between subgroups of paediatric fungaemias (neonates versus ICU children, paediatric cancer and adult cancer fungaemias). The $\chi^{2}$ test was used in multivariate analysis, with Mantel-Haenzsel modification, and where the cell size was $<5$, Fisher's exact test was used; $p$ values $\leqslant 0.05$ were considered to be significant.

\section{Results}

\section{Aetiology and antifungal susceptibility}

A total of 201 paediatric fungaemias was seen from 1989 to 2001 in the seven paediatric clinics and departments, in 10-day-old to 17-year-old children. Of these, 101 occurred in neonates, 40 in children with cancer and 51 in surgical ICUs. In aetiology, C. albicans was dominant and caused 144 (71.1\%) of the 201 fungaemias, followed by C. parapsilosis, C. tropicalis, C. glabrata, C. krusei, C. guilliermondii (Table 1). Non-albicans Candida spp. (NAC) caused 48 fungaemias and yeasts other than Candida spp. caused 7 fungaemias (Trichosporon beigelii, 4; Blastoschizomyces capitatus, 1; Rhodotorula rubra, 1; Cryptococcus laurentii, 1). Two episodes were caused by the mould Fusarium dimerum. However, there was a clear difference in the proportion of different species among the subgroups of paediatric fungaemia: C. albicans caused $83.3 \%$ of fungaemia in neonates but only $40.2 \%$ of those in children with cancer $(p<0.001)$. NAC were responsible for $40.2 \%$ of the fungaemias in children with cancer but for only $18.8-20 \%$ of fungaemias in neonates or children in ICUs $(\mathrm{p}<0.002)$ and organisms other than Candida spp. caused $14.8 \%$ of the fungaemias in children with cancer but none in the subgroup of neonatal fungaemia $(\mathrm{p}<0.002)$.

Table 2 shows the antifungal susceptibility of Candida spp. bloodstream isolates from 201 paediatric patients. Of the 298 isolates obtained, 220 were tested with fluconazole: $100 \%$ of C. albicans and $87.5 \%$ of NAC 
Table 1. Aetiology of 201 cases of paediatric fungaemia

\begin{tabular}{|c|c|c|c|c|}
\hline \multirow[b]{2}{*}{ Species } & \multicolumn{3}{|c|}{ Number of cases in } & \multirow[b]{2}{*}{ Total } \\
\hline & $\begin{array}{l}\text { Neonates } \\
\text { (110) }\end{array}$ & $\begin{array}{c}\text { Cancer patients } \\
(51)\end{array}$ & $\begin{array}{l}\text { Children in ICU } \\
\text { after surgery/ } \\
\text { trauma/coma ( } 40)\end{array}$ & \\
\hline C. albicans & 91 & $17(33.3 \%)$ & $32(80.0 \%)$ & $140(69.9 \%)$ \\
\hline C. parapsilosis & 15 & 6 & 8 & 29 \\
\hline C. tropicalis & 4 & 5 & 0 & 9 \\
\hline C. krusei & 0 & 5 & 0 & 5 \\
\hline C. glabrata & 0 & 4 & 0 & 4 \\
\hline C. guilliermondii & 0 & 4 & 0 & 4 \\
\hline Non-albicans Candida spp. (subtotal) & 12 & $24(46.6 \%)$ & $8(20.0 \%)$ & $51(25.1 \%)$ \\
\hline Trichosporon beigelii & 0 & 5 & 0 & 2 \\
\hline Rhodotorula rubra & 0 & 1 & 0 & 1 \\
\hline Blastoschizomyces capitatus & 0 & 2 & 0 & 1 \\
\hline Cryptococcus laurentii & 0 & 1 & 0 & 1 \\
\hline Non-Candida spp. (subtotal) & 0 & $9(18.0 \%)$ & 0 & $9(4.5 \%)$ \\
\hline Fusarium dimerum & 0 & 1 & 0 & 1 \\
\hline
\end{tabular}

were susceptible (S) or susceptible-dose-dependent (SDD) and $12.5 \%$ were resistant (MIC $>32 \mu \mathrm{g} / \mathrm{mL}$ ). None of the NAC in neonates but $12.5 \%$ of isolates from children from ICUs and $23.5 \%$ from children with cancer were resistant to fluconazole $(\mathrm{p}<0.045$ and 0.01 , respectively).

\section{Clinical characteristics and outcome in neonatal fungaemias}

Sixty-eight $(60 \%)$ of the 110 neonates were premature babies (29-35 weeks gestation) with very low birth weight $(750-1500 \mathrm{~g})$. All neonates were on TPN and the majority of neonates were artificially ventilated for 2-42 days (median 11 days). A positive BC for yeasts occurred 5-41 days (median 19) after birth. $C$. albicans was isolated in $91(83.3 \%)$ and NAC (mainly C. parapsilosis) in 19 (18.8\%) of neonates. All babies were pre-treated for 5-14 days with broad-spectrum antibiotics before developing fungaemia and 101 babies (92\%) were colonised with Candida spp. 5-14 days before the development of fungaemia.

In 18 neonates $(17.8 \%)$ fungaemia was complicated by Candida meningitis or meningo-encephalitis. In 79 neonates $(71.9 \%)$, complications of fungaemia (lung infiltrates, liver lesions, septic shock, etc.) appeared. Thirty-nine of 110 neonates died, 25 of them due to fungal infection (12.8\% attributable mortality) and 14 $(13.6 \%)$ because of underlying disease (severe prematurity, accompanied by fungaemia). Attributable mortality of children with cancer and fungaemia was similar in comparison to other children (10-11.6\%).

\section{Clinical characteristics and outcome of fungaemias in paediatric cancer patients}

Fungaemia was seen in 51 children with cancer. The following organisms were isolated (three episodes were polyfungal): C. albicans, 21; C. parapsilosis, $7 ; C$. tropicalis, $5 ; \quad$ C. krusei, $3 ; C$. glabrata, $3 ; C$. guilliermondii, 3 (total NAC $=21$ ); non-Candida spp., 7 (Rhodotorula rubra, 1; Blastoschizomyces capitatus, 1; Trichosporon beigelii, 4; Cryptococcus laurentii, 1); moulds (Fusarium spp.) in two children (Table 1). Underlying diseases in 51 children with cancer (1-17 years old) were: solid tumours, 31; leukaemia, 17; lymphoma, 3. Breakthrough fungaemia occured in 21 children with cancer: Fusarium spp., 2; C. albicans, 8; T. beigelii, 3; C. tropicalis, 4; Cryptococcus spp., 1; B. capitatus, $1 ; C$. parapsilosis, 1 . Sixteen children died of fungaemia, and only six of an underlying disease.

Table 2. Susceptibility to fluconazole of Candida spp. from paediatric fungaemia

\begin{tabular}{|c|c|c|c|c|c|}
\hline Parameter & Total & $\begin{array}{l}\text { Susceptible } \\
<16 \mathrm{mg} / \mathrm{L}\end{array}$ & $\begin{array}{c}\mathrm{SDD} \\
16-32 \mathrm{mg} / \mathrm{L}\end{array}$ & $\begin{array}{c}\text { Resistant } \\
\geqslant 64 \mathrm{mg} / \mathrm{L}\end{array}$ & $\begin{array}{l}\text { Group of } \\
\text { patients }\end{array}$ \\
\hline Total number of isolates & 298 & & & & \\
\hline Number of isolates tested & 220 & 180 & 35 & 5 & $\mathrm{~A}(\mathrm{~B}+\mathrm{C}+\mathrm{D})$ \\
\hline C. albicans & 181 & $160(88.2)$ & $21(11.8)$ & 0 & \\
\hline Non-albicans Candida spp. & 39 & $20(51.5)$ & $14(35.5)$ & $5(12.5)$ & \\
\hline Isolates from neonates & & & & & $\mathrm{B}$ \\
\hline C. albicans & 131 & 121 & 10 & 0 & \\
\hline Non-albicans Candida spp. & 10 & $6(60.0)$ & $4(40.0)$ & $0^{*}$ & \\
\hline Isolates from children with cancer & & & & & $\mathrm{C}$ \\
\hline C. albicans & 29 & 21 & 8 & 0 & \\
\hline Non-albicans Candida spp. & 21 & $10(43.2)$ & $7(33.3)$ & $4(23.5)^{*}$ & \\
\hline Isolates from children in ICU after surgery/trauma/coma & & & & & $\mathrm{D}$ \\
\hline C. albicans & 21 & 18 & 3 & 0 & \\
\hline Non-albicans Candida spp. & 8 & $4(50.0)$ & $3(37.5)$ & $1(12.5)$ & \\
\hline
\end{tabular}

${ }^{*} \mathrm{p}<0.045$ B versus A and D versus $\mathrm{B} ; \mathrm{p}<0.01 \mathrm{~B}$ versus $\mathrm{C}$. 


\section{Subgroup of children in paediatric ICU (after surgery or trauma)}

Of 40 critically ill children ( 2 months -4 years old) with surgical ICU-associated fungaemia, 16 had inborn malformations, 2 ileus, 7 craniocerebral trauma, 4 acute renal failure and 11 bacterial sepsis. Two were on dialysis, 19 had AV, 20 had TPN through CVC, and all received broad-spectrum antibiotics 9-13 days before the development of fungaemia. C. albicans was isolated from blood cultures from 32 children and $C$. parapsilosis from 8 . Ten children died of fungaemia, five died of underlying disease with fungaemia and 25 recovered. The attributable mortality of this subgroup of children was similar to that of the neonates.

\section{Comparison between neonates and children in ICUs with fungaemia}

When comparing risk factors associated with fungaemia in neonates versus children in ICUs after surgery, CVC insertion and TPN $(\mathrm{p}<0.0001)$ were more frequently observed in neonates (Table 3). In contrast, prior prophylaxis or therapy with fluconazole (breakthrough fungaemia) was more frequently observed among children in ICUs $(12.5 \%$ versus $5.5 \%$, $\mathrm{p}<0.035)$. Emergency (non-elective) surgery (62.6 versus $9.8 \%$ ) and coma (22.8 versus $1.3 \%$ ) were seen more frequently in children after surgery in ICUs $(p<0.0001$ and 0.0015$)$ despite the fact that both overall and attributable mortality were similar (12.5 versus $13.6 \%$, NS for crude and 22.8 versus $25 \%$, NS for attributable mortality).

\section{Comparison between fungaemia in adults and children with cancer}

A separate univariate analysis compared the risk factors and outcomes of the 51 cases of fungaemia in children with cancer versus 130 adult fungaemia patients during the same period, based on a national adult fungaemia survey (Table 4). The inclusion criterion for this group of fungaemia was cancer as underlying disease. The

Table 3. Comparison of demographics, clinical characteristics and risk factors of fungaemia in neonates versus children in ICU

\begin{tabular}{|c|c|c|c|}
\hline \multirow[b]{2}{*}{ Parameter } & \multicolumn{2}{|c|}{ Number $(\%)$ of cases in } & \multirow[b]{2}{*}{$\mathrm{p}$ value } \\
\hline & $\begin{array}{l}\text { neonates }^{\dagger} \\
(\mathrm{n}=110)\end{array}$ & $\begin{array}{l}\text { children with } \\
\text { surgery or trauma } \\
\text { (ICU; 40) }\end{array}$ & \\
\hline \multicolumn{4}{|l|}{ Risk factors } \\
\hline Corticosteroids & $27(25.5)$ & $5(12.5)$ & NS \\
\hline $\mathrm{CVC}$ & $110(100.0)$ & $24(60.0)$ & $<0.0001$ \\
\hline AV & $55(50.0)$ & $19(47.5)$ & NS \\
\hline TPN & $110(100.0)$ & $20(50.0)$ & $<0.0001$ \\
\hline Number of positive BC/episode & 1.9 & 1.8 & NS \\
\hline $\begin{array}{l}\text { Length of hospital stay, when the } \\
\text { first positive BC appeared (days) }\end{array}$ & 17.5 & 16.0 & NS \\
\hline Prior colonisation with yeasts & $101(92.0)$ & $38(95.0)$ & NS \\
\hline Prior antibiotic therapy & $110(100.0)$ & $40(100.0)$ & NS \\
\hline Antifungal prophylaxis/therapy* & $15(13.7)$ & $9(22.5)$ & NS \\
\hline $\mathrm{KET} 5 \mathrm{mg} / \mathrm{kg}$ bid & $7(6.7)$ & $1(2.5)$ & NS \\
\hline FLU $6 \mathrm{mg} / \mathrm{kg}$ od & $6(5.5)$ & $5(12.5)$ & $<0.035$ \\
\hline $\mathrm{AmB} \quad 0.2-0.5 \mathrm{mg} / \mathrm{kg}$ od & $2(1.8)$ & $1(2.5)$ & NS \\
\hline Emergency surgery & $10(9.8)$ & $25(62.5)$ & $<0.0001$ \\
\hline CNS, GIT or other malformations & $20(19.6)$ & $17(42.5)$ & NS \\
\hline Coma & $1(0.9)$ & $9(22.5)$ & $<0.0015$ \\
\hline Two or more positive $\mathrm{BC}$ & $23(21.0)$ & $12(30.0)$ & NS \\
\hline C. albicans & $91(83.3)$ & $32(80.0)$ & NS \\
\hline Non-albicans Candida spp. & $19(18.8)$ & $8(20.0)$ & NS \\
\hline Catheter-related & $2(1.8)$ & $3(7.5)$ & NS \\
\hline Complications (total) & 79 (71.9) & $18(45.0)$ & $<0.02$ \\
\hline Septic shock & $19(18.1)$ & $7(17.5)$ & NS \\
\hline Meningitis & $18(17.1)$ & $1(2.5)$ & NS \\
\hline Nephritis & $6(5.0)$ & $3(7.5)$ & NS \\
\hline Hepatic lesions & $10(9.0)$ & $1(2.5)$ & NS \\
\hline Lung lesions & $23(17.8)$ & $1(2.5)$ & NS \\
\hline Other & $3(2.9)$ & $4(10.0)$ & NS \\
\hline \multicolumn{4}{|l|}{ Outcome } \\
\hline Recovery & $71(63.6)$ & $25(62.5)$ & NS \\
\hline Death from underlying disease & $14(13.6)$ & $5(12.5)$ & NS \\
\hline Death from fungaemia & $25(22.8)$ & $10(25.0)$ & NS \\
\hline Overall mortality & $39(36.4)$ & $15(37.5)$ & NS \\
\hline
\end{tabular}

$\mathrm{CVC}$, central or unbilical venous catheter; $\mathrm{AV}$, artificial ventilation; $\mathrm{TPN}$, total parentera nutrition; BC, blood culture; KET, ketoconazole; FLU, fluconazole; AmB, amphotericin B; CNS, central nervous system; GIT, gastrointestinal tract; ICU, paediatric Intensive Care Unit. *Breakthrough.

$\dagger 90$ cases analysed partially [17] and 6 cases published in [19]. 
Table 4. Paediatric versus adult fungaemias in cancer patients: risk factors, therapy and outcome

\begin{tabular}{|c|c|c|c|}
\hline \multirow[b]{2}{*}{ Parameter } & \multicolumn{2}{|c|}{ Number $(\%)$ of cases in } & \multirow[b]{2}{*}{$\mathrm{p}$ value } \\
\hline & $\begin{array}{l}\text { children } \\
(\mathrm{n}=51)\end{array}$ & $\begin{array}{c}\text { adults } \\
(\mathrm{n}=130)\end{array}$ & \\
\hline \multicolumn{4}{|l|}{ Risk factors } \\
\hline Corticosteroids & $19(38.4)$ & $24(18.5)$ & $<0.015$ \\
\hline $\mathrm{CVC}$ & $34(66.6)$ & $109(83.8)$ & NS \\
\hline $\mathrm{AV}$ & $5(9.9)$ & $5(3.8)$ & NS \\
\hline TPN & $6(11.9)$ & $14(10.8)$ & NS \\
\hline Antineoplastic chemotherapy & $36(70.5)$ & $72(55.4)$ & NS \\
\hline Number of positive BC per episode & 1.9 & 1.7 & NS \\
\hline $\begin{array}{l}\text { Length of hospital stay, when the } \\
\text { first positive BC appeared (days) }\end{array}$ & 13.5 & 10.5 & NS \\
\hline Prior colonisation with yeasts & $20(39.7)$ & $76(58.5)$ & NS \\
\hline Prior antibiotic therapy & $37(73.1)$ & $85(65.4)$ & NS \\
\hline Neutropenia & $20(39.5)$ & $62(47.7)$ & NS \\
\hline $\begin{array}{l}\text { Antifungal prophylaxis - } \\
\text { breakthrough }\end{array}$ & $21(40.2)$ & $40(30.8)$ & NS \\
\hline KET & $10(19.7)$ & $10(7.7)$ & $<0.045$ \\
\hline FLU & $5(9.3)$ & $6(4.6)$ & NS \\
\hline ITR & $2(2.0)$ & $10(7.7)$ & NS \\
\hline $\mathrm{AmB}$ & $7(13.4)$ & $14(10.8)$ & \\
\hline Prior antibiotic prophylaxis (QUIN) & $14(26.8)$ & $35(26.9)$ & NS \\
\hline \multicolumn{4}{|l|}{ Underlying disease } \\
\hline Neoplasia - acute leukaemia & $16(31.9)$ & $24(18.5)$ & NS \\
\hline $\begin{array}{l}\text { Neoplasia - non-Hodgkin's } \\
\text { lymphoma }\end{array}$ & $5(9.3)$ & $21(16.2)$ & NS \\
\hline Neoplasia - solid tumour & $34(66.6)$ & $85(65.4)$ & \\
\hline \multicolumn{4}{|l|}{ Aetiology } \\
\hline Two or more positive $\mathrm{BC}$ & $10(19.7)$ & $24(18.5)$ & NS \\
\hline C. albicans & $21(40.2)$ & $76(58.5)$ & $<0.03$ \\
\hline Non-albicans Candida spp. & $21(40.2)$ & $39(30.0)$ & NS \\
\hline Non-Candida yeast spp. & $7(14.8)$ & $11(8.5)$ & NS \\
\hline Moulds & $2(4.0)$ & $4(3.1)$ & NS \\
\hline Catheter-related & $7(13.4)$ & $14(10.8)$ & NS \\
\hline Complications (total) & $16(31.9)$ & $32(24.6)$ & NS \\
\hline Septic shock & $10(19.7)$ & $14(10.8)$ & NS \\
\hline Meningitis & $7(13.4)$ & $1(0.8)$ & $<0.008$ \\
\hline Nephritis & $0(0)$ & $3(2.3)$ & NS \\
\hline Hepatic lesions & $0(0)$ & $3(2.3)$ & NS \\
\hline Lung lesions & $1(2.0)$ & $5(3.9)$ & NS \\
\hline Endophthalmitis & $0(0)$ & $1(0.8)$ & NS \\
\hline Endocarditis & $0(0)$ & $1(0.8)$ & NS \\
\hline \multicolumn{4}{|l|}{ Outcome } \\
\hline Recovery & $29(57.5)$ & $77(57.8)$ & NS \\
\hline Death from underlying disease & $6(10.6)$ & $17(13.1)$ & NS \\
\hline Death from fungaemia & $16(31.9)$ & $30(29.1)$ & \\
\hline
\end{tabular}

See footnotes to Table 3 for abbreviations.

QUIN, quinolone; ITR, itraconazole.

proportions of leukaemias, BMT, lymphoma and solid tumours were similar in both groups.

Several risk factors showed significant differences between childhood fungaemia and adult fungaemia in cancer patients: (i) corticosteroids in therapy ( $<<0.015$ ), (ii) breakthrough fungaemia during ketoconazole prophylaxis $(\mathrm{p}<0.0)$ and (iii) meningitis as a complication of fungaemia $(p<0.008)$ occurred more frequently in paediatric fungaemia. However, overall mortality in children with cancer and fungaemia in comparison to adults with cancer and fungaemia was similar (42.5 versus $42.2 \%)$. C. albicans was isolated more frequently from adults (58.5 versus $36.6 \%$, $\mathrm{p}<0.03)$.
The proportion of breakthrough fungaemia was relatively high in all subgroups and occurred in 21 of 51 children with cancer and 40 of 130 adults with cancer (40.2 versus $30.8 \%$, NS). When breakthrough fungaemia occurred during ketoconazole prophylaxis, it was observed more frequently in children than in adults (19.7 versus $7.7 \%, \mathrm{p}<0.045)$.

\section{Discussion}

To our knowledge, this is the largest group of fungaemias in children published (201 cases) [17-19]. However, although previously reported cases of fungaemia in children have comprised small groups (1-8) 
[14-19], they have provided useful information as they describe fungaemia in stratified risk groups of children with similar underlying disease. Most studies have described risk factors that are common to paediatric and adult fungal bloodstream infections (CVC, prior treatment with broad-spectrum antibiotics, neutropenia, gastrointestinal surgery, corticosteroid therapy, etc.). However, two studies of fungaemia in general paediatric populations $[2,3]$ have described two specific risk factors for paediatric fungaemia - TPN and AV, which are seen less frequently in adult fungaemia. Breakthrough fungaemia in the previous studies was due mainly to organisms other than C. albicans [2-7] and was relatively frequent in the present study, occurring in 21 of 51 children but in only 4 of 130 adults with a malignant disease, as well as in 15 of 110 children with neonatal fungaemia. Among the cases of breakthrough fungaemia, some appeared on days 3-5 of prophylaxis with oral antifungal agents. This may at least partly be the reason for the lack of protection in these patients. As most of the fungal species isolated from the cases of breakthrough fungaemia are known to be susceptible in vitro to fluconazole and ketoconazole, which was used for prophylaxis, it can be assumed that decreased absorption of imidazoles in critically ill children and in children receiving corticosteroids with antacids (many with cancer and breakthrough fungaemia during prophylaxis with ketoconazole) probably resulted in insufficient serum levels of this antifungal agent, thereby leading to breakthrough fungaemia. Thus, it seems questionable whether prophylaxis with ketoconazole provides protection against fungaemia in these categories of patients [10]. Fluconazole, which is better absorbed, may offer better protection and can be given parenterally. However, fluconazole also failed to protect against fungaemia in 16 children. Sixty-six of 110 neonates were treated with fluconazole 6$10 \mathrm{mg} / \mathrm{kg} /$ day, 6 in combination with amphotericin $\mathrm{B}$, once daily. As there is only one report on the use of fluconazole in neonates [16] and 16 of the neonates in the present study who were treated with fluconazole also had meningitis, these data suggest that fluconazole may also be considered as suitable therapy for fungaemia and meningitis in premature neonates.

Comparing aetiology, there were differences between the subgroups of neonatal and non-neonatal fungaemia. Neonatal fungaemia was predominantly caused by $C$. albicans $(83.3 \%)$, whereas fungaemia in children with cancer was caused by C. albicans in only $40.2 \%$ of cases. The remaining cases in non-neonates were associated with non-Candida spp. The reason for this is probably the fact that neonates, who represented the majority of patients with fungaemia, were infected perinatally and $C$. albicans is the major species isolated in mothers [13]. Previous cytotoxic chemotherapy with prophylactically administered azoles and empiric amphotericin B therapy in adults may also contribute to the fact that yeasts other than $C$. albicans were prevalent in children and adults who had cancer, despite the fact that six of seven other studies of neonatal and paediatric fungaemia $[1-3,8-10]$ still found $C$. albicans to be the predominant pathogen (Table 3.).

Previously published studies have shown similar attributable mortality due to fungaemia in children $(19-54 \%)$ [2-8] and in adults $(23-50 \%)[11,12]$. In the present study, attributable mortality in children with cancer and fungaemia was similar to adults with cancer and fungaemia. Furthermore, the outcome in children with cancer showed no difference compared to neonates. Probably, neutropenia and cancer as underlying diseases represent similar risks for the development of invasive fungal infections to those risk factors associated with prematurity, such as low birth weight, TPN and AV. Further studies on the comparison between paediatric and adult fungaemia in a stratified patient population (e.g., leukaemic children versus leukaemic adults), may find more differences in risk factors and outcome between fungaemia in paediatric and adult patient populations. However, some of the differences in aetiology and in antifungal susceptibility that were observed in the present study warrant prudent use of prophylactic and empiric antifungal agents in critically ill children.

This study was supported by grant no. 3096/5074 from the Ministry of Education (VEGA) and Inter-Copernicus from the EC (PL 970002) and by grant nos 1/3094-1/5074-6028 from the Ministry of Education, Slovakia and PL 97 from the EC.

\section{References}

1. Walsh TJ, Gonzalez C, Roilides E et al. Fungemia in children infected with the human immunodeficiency virus: new epidemiologic patterns, emerging pathogens, and improved outcome with antifungal therapy. Clin Infect Dis 1995; 20: 900-906.

2. Stamos JK, Rowley AH. Candidemia in a pediatric population. Clin Infect Dis 1995; 20: 571-575.

3. Roilides E, Kadiltsoghou I, Zakides D, Bibaski E. Invasive candidiosis in pediatric patients. Clin Microbiol Infect 1997; 3: 192-197.

4. Pizzo PA, Walsh TJ. Fungal infections in the pediatric cancer patient. Semin Oncol 1990; 17 Suppl 6: 6-9.

5. Faix RG. Invasive neonatal candidiasis: comparison of albicans and parapsilosis infection. Pediatr Infect Dis J 1992; 11: 88-93.

6. Dato VM, Dajani AS. Candidemia in children with central venous catheter: role of catheter removal and amphotericin B therapy. Pediatr Infect Dis J 1990; 9: 309-314.

7. Butler KM, Baker CJ. Candida: an increasingly important pathogen in the nursery. Pediatr Clin North Am 1988; 35: $543-563$.

8. Mokkadas FM, Ramadan S, Sanyal SC. Candidaemia in pediatric surgery patients. Fifth Symposium on Trends in Invasive Fungal Infections, Barcelona 6-8 Nov. 1997: Abstract no. 45.

9. Lecciones JA, Lee JW, Navarro EE et al. Vascular catheterassociated fungemia in patients with cancer: analysis of 155 episodes. Clin Infect Dis 1992; 14: 875-883.

10. Fraser VJ, Jones M, Dunkel J, Storfer S, Medoff G, Dunagan WC. Candidemia in a tertiary care hospital: epidemiology, risk factors and predictors of mortality. Clin Infect Dis 1992; 15: 414-421.

11. Krcmery V, Oravcova E, Spanik S et al. Nosocomial breakthrough fungaemia during antifungal prophylaxis or empirical antifungal therapy in 41 cancer patients receiving antineoplastic chemotherapy: analysis of aetiology, risk factors and 
outcome. J Antimicrob Chemother 1998; 41: 373-380.

12. Eppes SC, Troutman JL, Gutman LT. Outcome of treatment of candidemia in children whose central catheters were removed or retained. Pediatr Infect Dis J 1989; 8: 99-104.

13. Turner RB, Donowitz LG, Hendley JO. Consequences of candidemia for pediatric patients. Am J Dis Child 1985; 139: 178-180.

14. Johnson DE, Thompson TR, Green TP, Ferrieri P. Systemic candidiasis in very low-birth-weight infants $(<1500$ grams $)$. Pediatrics 1984; 73: 138-143.

15. Baley JE, Kliegman RM, Fanaroff AA. Disseminated fungal infections in very low-birth-weight infants: therapeutic toxicity. Pediatrics 1984; 73: 153-157.
16. Fasano C, O'Keefe J, Gibbs D. Fluconazole treatment of neonates with severe fungal infections not treatable with conventional agents. Eur J Clin Microbiol Infect Dis 1993; 13: 351-354.

17. Krčméry V, Frič $\mathrm{M}$, Pisarčikov' $\mathrm{M}$ et al. Fungemia in neonates: report of 80 cases from seven University hospitals. Pediatrics 2000; 105: 913-914.

18. Spanik S, Kaiserova E, Grausova S et al. Fungemia in children with neoplastic diseases. Pediatr Infect Dis J 1998; 17: 442.

19. Krčmery V, Huttova $M$, Matziola $F$ et al. Breakthrough fungaemia in neonates and infants caused by $C$. albicans and C. parapsilosis. J Antimicrob Chemother 2001; 48: $521-525$ 